\title{
Molecular detection and seasonal distribution of lumpy skin disease virus in cattle breeds in Turkey
}

\author{
HARUN ALBAYRAK, EMRE OZAN*, HAMZA KADI*, ABDULLAH CAVUNT*, \\ CUNEYT TAMER, MEHMET TUTUNCU**
}

\author{
Department of Virology, **Department of Internal Medicine, Faculty of Veterinary Medicine, \\ Ondokuz Mayis University, 55200, Samsun, Turkey \\ *Veterinary Control Institute, 55200, Samsun, Turkey
}

Albayrak H., Ozan E., Kadi H., Cavunt A., Tamer C., Tutuncu M.

\section{Molecular detection and seasonal distribution of lumpy skin disease virus in cattle breeds in Turkey}

Summary

The aim of this study was to investigate the prevalence and distribution patterns of LSDV infections in the provinces of northern Turkey, and to detect the factors influencing the epidemiology of LSD virus infections (age, breed, season, climate, geography, population dynamic, animal movement), as well as to assess the diagnostic value of the sampled materials in the diagnosis of LSDV infections. Lumpy skin disease (LSD) is an economically important cattle disease. The disease is endemic in many African countries, but outbreaks have also been reported in Turkey and the Middle East. In this study, a total of 564 samples (skin, blood and lung) from different cattle breeds (Jersey, Holstein-Friesian, Anatolian Black, Simmental and Brown Swiss) $(n=465)$ in the many herds suspected of lumpy skin disease virus (LSDV) infection as clinically and macroscopic pathologic remarks, housed in the 7 different provinces of northern Turkey, were used for gel based conventional polymerase chain reaction (PCR). LSDV nucleic acid was detected in 259 of 564 (45.92\%) materials by PCR. According to the result of PCR, the LSDV infection was diagnosed in 54.62\% (254/465) of the sampled animals. The diagnostic value of necropsy and clinical materials such as skin and lung were determined as more valuable diagnostic materials in the diagnosis of LSDV infection by PCR. Data showed that LSDV infection was widespread in the provinces of northern Turkey and that the prevalence of the infection in the region varies in accordance with factors such as geographical conditions (climate, season, location etc.) and the method of breeding.

Keywords: cattle, cattle breeds, LSDV, PCR, Turkey

Lumpy skin disease (LSD) is an acute disease among cattle characterised by high fever, nodules on the skin, enlargement of superficial lymph nodes, salivation, lachrymation, rhinitis and keratitis. Pox lesions may also be present in the pharynx, larynx, trachea, lungs and throughout the alimentary tract $(2,19)$. The disease is endemic in many African countries. Since 2000, it has spread to the Middle East, was confirmed in Turkey in 2013, and is now prevalent in many countries in the European Union $(9,18,20)$.

The virus is a member of the Capripoxvirus genus within the Chordopoxvirinae subfamily of the Poxviridae family (5). All cattle breeds and age groups are susceptible; however, the disease is more severe in young animals and cows in the peak of lactation (12). The incubation period under field conditions is unknown, but varies from 1 to 4 weeks under experimental conditions $(7,19,20)$. The World Organization for Animal Health (OIE) categorizes LSD as a notifiable disease because of the substantial economic impact of an outbreak. Haematophagous insects have been primarily associated with the transmission of LSDV (6). Ticks have recently been implicated in the transmission of LSDV like other arboviral diseases $(1,10,20,21)$. The disease is of economic importance due to the severe damage to hides, reduced milk and meat production, temporary infertility and trade losses due to movement restrictions placed on cattle from affected areas $(8,14)$. Since 2014 , a total of 340 LSD outbreaks have been documented in northern Turkey (Sivas, Ordu, Samsun, Giresun, Amasya, Tokat, Rize). Three hundred and ten of them were declared in 2014 (15). Currently, there is no recorded data regarding the prevalence and distribution of LSDV infections among cattle breeds in Turkey. The aim of this study was to investigate the prevalence and distribution patterns of 


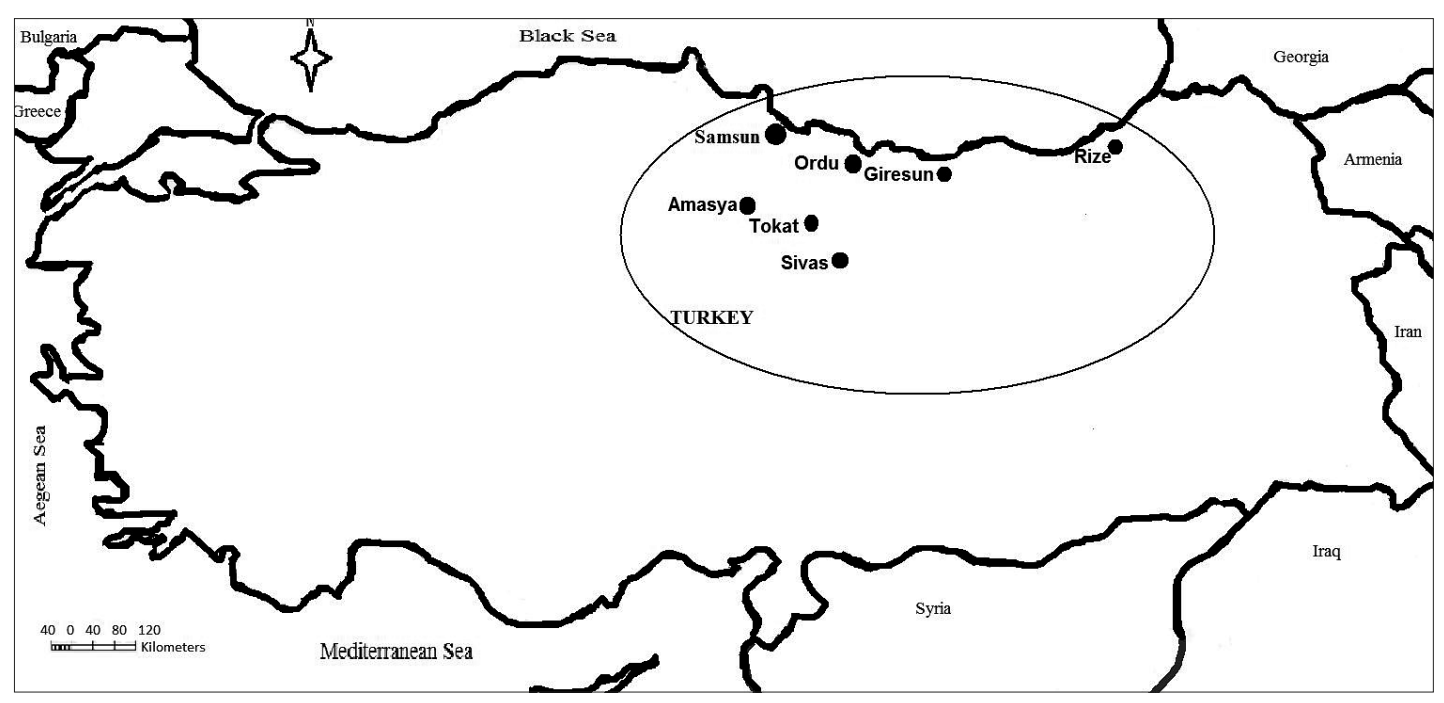

Fig. 1. The map of the locations where samples were collected for the diagnosis of LSDV
MagNa Lyser (Roche, Mannheim, Germany). Homogenates were centrifuged in Eppendorf tubes at $12,000 \times \mathrm{g}$ for 3 min to remove the suspended solids, without removing the beads. The supernatants were stored at $-80^{\circ} \mathrm{C}$ until testing. Blood samples were taken from the jugular veins of the animals. Blood tubes were centrifuged at $3,000 \times \mathrm{g}$ for $10 \mathrm{~min}$, and the samples were transferred to sterile tubes and stored at
LSDV infections in the provinces of northern Turkey, and to detect the factors influencing the epidemiology of LSD virus infections (age, breed, season, climate, geography, population dynamic, animal movement), as well as to assess the diagnostic value of the sampled materials in the diagnosis of LSDV infections.

\section{Material and methods}

Ethical committee approval. The study protocols and experimental procedures were approved by the Samsun Veterinary Control Institute Scientific Ethics Committee (No: 2014/34).

Sample collection and processing. Samples were taken from animals from herds which had experienced previous outbreaks of LSD in 7 provinces (Sivas, Ordu, Samsun, Giresun, Amasya, Tokat, Rize) (Fig. 1). Clinical remarks and necroscopic findings based on observations of these animals are shown in Figure 2. The samples were collected between June, 2014 and January, 2015 in northern Turkey (Tab. 1). A total of 564 sample materials (359 skin, 35 lung, 170 blood samples with EDTA) from 465 animals, including adult cattle and calves, were used in this study. Skin and lung samples were placed in $2 \mathrm{ml}$ of PBS diluent with MagNA Lyser Green Beads (Roche, Mannheim, Germany) and were homogenized at 3,000 $\times \mathrm{g}$ for $3 \mathrm{~min}$ by $-20^{\circ} \mathrm{C}$ until used. The positive control DNA of LSDV was kindly provided by Dr. Fahriye Saraç (Pendik Veterinary Control Institute, Istanbul, Turkey).

DNA extraction and PCR assay. The nucleic acid was extracted using a modified extraction method described by Tuppurainen et al. (22). Proteins were digested by adding 2-4 IU of proteinase $\mathrm{K}$ (Invitrogen, $20 \mathrm{mg} / \mathrm{ml}$ ), and the samples were incubated at $56^{\circ} \mathrm{C}$ overnight. The DNA was precipitated in two volumes of $100 \%$ ethanol and $1 / 10$ of $3 \mathrm{M}$ sodium acetate $(\mathrm{pH}$ 5.3). DNA amplification was performed using primers developed from the viral attachment gene. The primers have the following sequences: forward primer: 5'-TCCGAGCTCTTTCCTGATTTTTCTTACTAT-3' and reverse primer: 5'-TATGGTACCTAAATTATATACGTAAATAAC-3'. PCR products were analysed on agarose gel $(1.5 \%)$ electrophoresis at $80 \mathrm{~V}$ for $30 \mathrm{~min}$. The positive samples gave products of the expected size of $192 \mathrm{bp}$ (13).

\section{Results and discussion}

Positive PCR results, indicated by the amplification of a 192-bp genome fragment, were detected in 259 sampled materials out of 564 . The positivity rates were estimated as $45.92 \%(259 / 564), 54.62 \%(254 / 465)$ for the sampled materials and animals, respectively (Tab. 1). LSD nucleic acid positive results were

Tab. 1. Seasonal distribution of lumpy skin disease

\begin{tabular}{|c|c|c|c|c|c|c|c|c|c|}
\hline \multirow{2}{*}{ Provinces } & \multicolumn{8}{|c|}{ Months } & \multirow{2}{*}{ Total } \\
\hline & June & July & August & September & October & November & December & January & \\
\hline Sivas & - & & $0 / 2(-)$ & $77 / 90$ (85.56) & $53 / 84(63.10)$ & $22 / 41(53.66)$ & 6/18 (33.33) & $3 / 6(50.00)$ & $161 / 241(66.80)^{*}$ \\
\hline Ordu & - & - & - & 2/12 (16.67) & $2 / 4(50.00)$ & 9/17 (52.94) & - & - & $13 / 33$ (39.39) \\
\hline Samsun & - & - & - & $3 / 7(42.86)$ & $1 / 9(11.11)$ & $6 / 12(50.00)$ & $5 / 12$ (41.67) & $2 / 6(33.33)$ & $17 / 46(36.96)$ \\
\hline Giresun & $0 / 1(-)$ & - & - & $1 / 2(50.00)$ & $0 / 2(-)$ & $0 / 8(-)$ & $0 / 7(-)$ & - & $1 / 20(5.00)$ \\
\hline Amasya & - & - & - & $8 / 9(88.89)$ & $3 / 10(30.00)$ & $1 / 9(11.11)$ & $1 / 2(50.00)$ & - & $13 / 30(43.33)^{*}$ \\
\hline Tokat & - & - & - & 9/12 (75.00) & $8 / 17(47.06)$ & $15 / 22(68.19)$ & 9/18 (50.00) & $0 / 4(-)$ & $42 / 74(56.76)^{*}$ \\
\hline Rize & - & - & $1 / 1(100)$ & - & $6 / 16(37.50)$ & $0 / 3(-)$ & $1 / 2(50.00)$ & - & 7/21 (33.33) \\
\hline Total & $0 / 1(-)$ & - & $1 / 3(33.33)$ & $100 / 132(75.76)^{*}$ & $73 / 142(51.41)^{*}$ & $53 / 112(47.32)^{*}$ & $22 / 59$ (37.29) & $5 / 16(31.25)$ & $254 / 465$ (54.62) \\
\hline
\end{tabular}

Explanation: $* \mathrm{P}<0.01$ 
observed in $14.29 \%(5 / 35)$ of the lung samples, $67.41 \%$ $(242 / 359)$ of the skin samples and 5.29\% (9/170) of the blood samples from animals. Additionally, the prevalence of LSDV did not differ between male and female cattle (Fisher's exact test, $\mathrm{P}<0.05$ ). A higher positivity rate was detected in the Sivas province than in other provinces. Adult cattle displayed a higher prevalence, $55.42 \%(235 / 424)$, than calves under one year of age, $46.34 \%$ (19/41). This finding is in disagreement with a previous study that reported higher morbidities in the younger age categories (16). One possible reason for the lower prevalence of infection in calves could be the low frequency of pasture usage of calves in the region; however, adults are continuously in the pasture during the season.

In this study, double sample materials such as skin and blood, skin and lung, lung and blood were used in the diagnosis of LSDV infection as well. Positivity rates of $79.52 \%(66 / 83), 7.23 \%(6 / 83), 6.67 \%(1 / 15)$ were detected in the samples of skin, blood and lung samples, respectively. In determining whether seasonal transmission was significant, the chi-square test was used. Results from the chi-square test indicate that positivity rates from September, October and November were higher than those from other months $(\mathrm{P}<0.01)$ (Tab. 1). The positivity rates for Sivas, Tokat and Amasya provinces were higher than those than in other provinces $(\mathrm{P}<0.01)$. The positivity rates for
Brown Swiss, Anatolian Black and Holstein-Friesian were higher than those among other cattle breeds $(\mathrm{P}<0.01)$.

In outbreaks of the disease, it has been reported in many studies $(4,7)$ that morbidity and mortality of the LSD virus infection differs depending upon various factors (i.e. immune status of the hosts and the abundance of mechanical arthropod vectors) and usually ranges from $3 \%$ to $85 \%$. The mortality rate is generally low (1-3\%), but may sometimes reach $40 \%$ $(7,11,16,19)$. According to the local veterinarian, the morbidity rate reached $66.0 \%$ in the Sivas province and this rate is higher than that in other provines. The Sivas province is closer to the southern border of Turkey and has a higher cattle population compared to other provinces. Uncontrolled animal movement is also more common in the Sivas province. Mortality was observed in most of the herds exposed to natural LSDV infection. However, the highest mortality rate was observed among the Holstein-Friesian cattle breed at $10 \%$. It is unknown what genetic factors influence the severity of the disease $(2,17)$. This finding is in agreement with a previous report (16). It seemed that the Holstein-Friesian cattle breed examined in this study were more susceptible to the disease than other breeds, which is in agreement with previous reports stating that breed variation influences LSD susceptibility $(16,17)$. The overall case fatality rate in this

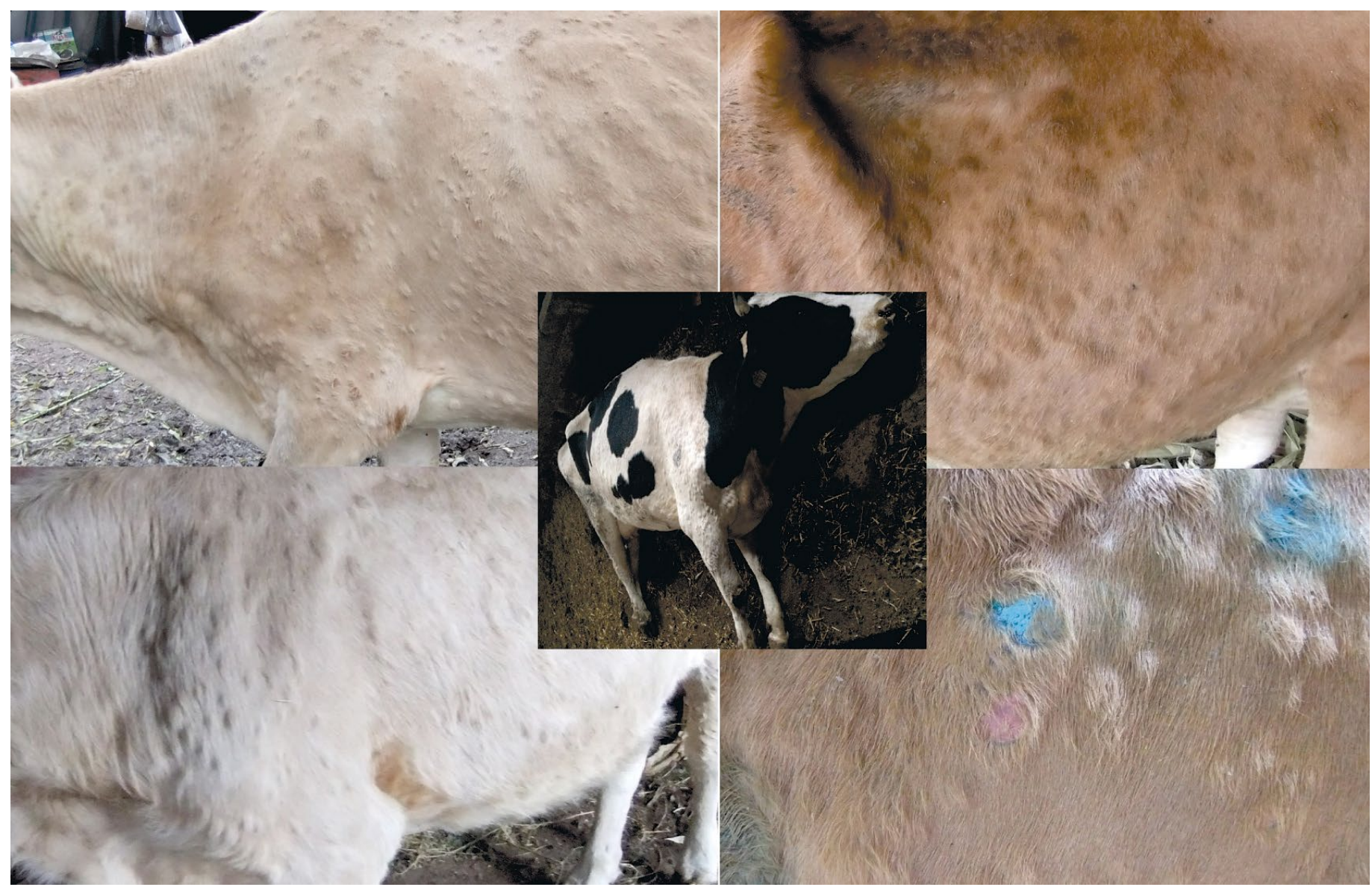

Fig. 2. Clinical findings observed in the sampled animals 
study were $54.62 \%$. This finding is in agreement with previous reports $(16,17)$.

In this study, different sample materials such as skin, lung and blood samples were used in the diagnosis of LSDV infection. Positivity rates of $67.41 \%(242 / 359)$, $14.29 \%(5 / 35), 5.29 \%(9 / 170)$ were detected in the samples of skin, lung and blood samples, respectively. Similarly, Bowden et al. (3) studied and reported that viral nucleic acid was detected in the sample of skin, lung, blood, etc. They also reported that skin and lung samples are preferred to the other samples for the necropsy sample. As it has already been reported by Bowden et al. (3), findings from our study suggest that skin samples are the most valuable diagnostic materials, and lung and blood samples follow in terms of diagnostic value.

Symptoms of LSDV infection such as fever, enlarged superficial lymph nodes, pox lesions in the skin and mucous membranes of the digestive and respiratory tracts, excessive salivation, lachrymation and nasal discharge $(2,7)$ were also noted in this study (Fig. 2). Although Davies (8) reported intrauterine infection of late-term fetuses among calves born with LSD lesions, the viral nucleic acid was detected in a newly-born calf ( 15 days of age) without ever displaying marked symptoms. This result may indicate intrauterine transmission in LSDV infections.

The precise origin of the LSD virus responsible for the outbreak in Turkey is unknown. However, it is possible that the disease was introduced into the country by infected cattle trafficking from Iraq and Syria. More than two million Syrian refugees have crossed into Turkey with their belongings including animals in the past four years. The uncontrolled movement of infected animals may be a factor in the spread of disease throughout various regions of Turkey. Due to civil war in Syria, there is no available data regarding LSDV, but the infection has been endemic in Iraq, Iran, Egypt, Jordan, Israel, Yemen, Sudan and Saudi Arabia for the last three years (9). It is feared that the disease could cross boundaries into neighbouring countries or spread rapidly throughout the region and become a pandemic. Recently, the disease was reported in Greece in 2015 (18). It is likely that this disease will spread to the rest of Europe.

The findings presented in this study suggest that LSD infection, which was first reported 2 years ago in Turkey, has spread more rapidly to the rest of the country. Current data in Turkey is insufficient to determine the region-based profile of LSDV infection. Taking the necessary precautions to prevent the virus from spreading, adopting swift and precise diagnostic modalities, and some particular practices (vaccination, etc.) play a significant role in the control of infection. These findings could be helpful to veterinary authorities in assessing the risk factors for LSDV, but to further understand LSDV outbreaks in Turkey, additional studies on major vectors (e.g. mosquitoes and ticks) are needed.

\section{References}

1. Albayrak H., Ozan E., Kurt M.: An antigenic investigation of Crimean-Congo haemorrhagic fever virus (CCHFV) in hard ticks from provinces in northern Turkey. Trop. Anim. Health Pro. 2010, 42, 1323-1325.

2.Babiuk S., Bowden T. R., Parkyn G., Dalman B., Manning L., Neufeld J., Embury-Hyatt C., Copps J., Boyle D. B.: Quantification of lumpy skin disease virus following experimental infection in cattle. Transbound. Emerg. Dis. 2008, 55, 299-307.

3.Bowden T. R., Babiuk S. L., Parkyn G. R., Copps J. S., Boyle D. B.: Capripoxvirus tissue tropism and shedding: a quantitative study in experimentally infected sheep and goats. Virology 2008, 371, 380-393.

4.Brenner J., Bellaiche M., Gross E., Elad D., Oved Z., Haimovitz M., Wasserman A., Friedgut O., Stram Y., Bumbarov V., Yadin H.: Appearance of skin lesions in cattle populations vaccinated against lumpy skin disease: statutory challenge. Vaccine 2009, 27, 1500-1503.

5. Buller R. M., Arif B. M., Black D. N., Dumbell K. R., Esposito J. J., Lefkowitz E. J., McFadden G., Moss B., Mercer A. A., Moyer R. W., Skinner M. A., Tripathy D. N.: Poxviridae, [in:] Fauquet C. M., Mayo M. A., Maniloff J., Desselberger U., Ball L. A. (eds): Virus Taxonomy: Eight Report of the International Committee on the Taxonomy of Viruses. Elsevier Academic Press, Oxford 2005, p. 117-133.

6. Chihota C. M., Rennie L. F., Kitching R. P., Mellor P. S.: Mechanical transmission of lumpy skin disease virus by Aedes aegypti (Diptera.: Culicidae). Epidemiol. Infect. 2001, 126, 317-321.

7. Coetzer J. A. W.: Lumpy skin disease, [in:] Coetzer J. A. W., Tustin R. C. (eds): Infectious Diseases of Livestock. University Press Southern Africa, Oxford 2004, p. 1268-1276.

8. Davies F. G.: Lumpy skin disease, an African capripox virus disease of cattle. Br. Vet. J. 1991, 147, 489-502.

9. EFSA: Scientific opinion on lumpy skin disease. EFSA Journal 2015, 13, 1-73.

10. Ergunay K., Whitehouse C. A., Ozkul A.: Current status of human arboviral diseases in Turkey. Vector-Borne Zoonot. 2010, 11, 731-741.

11. Gurcay M., Sait A., Parmaksız A., Kilic A.: The detection of lumpy skin disease virus infection by clinical findings and per method in Turkey. Kafkas Univ. Vet. Fak. Derg. 2015, 21, 417-420.

12. Hunter P., Wallace D.: Lumpy skin disease in Southern Africa: A review of the disease and aspects of control. J. S. Afr. Vet. Assoc. 2001, 72, 68-71.

13. Ireland D. C., Binepal Y. S.: Improved detection of capripoxvirus in biopsy samples by PCR. J. Virol. Methods 1998, 74, 1-7.

14. Kumar S. M.: An Outbreak of lumpy skin disease in a holstein dairy herd in Oman: A clinical report. Asian J. Anim. Vet. Adv. 2011, 6, 851-859.

15. Mafal: Ministry of Food, Agriculture and Livestock. The reports of the Animal Diseases Department, Annual Report 2016, 1, 1-7.

16. Sevik M., Dogan M.: Epidemiological and molecular studies on lumpy skin disease outbreaks in Turkey during 2014-2015. Transbound. Emerg. Dis. 2017, 64, 1268-1279

17. Tageldin M. H., Wallace D. B., Gerdes G. H., Putterill J. F., Greyling R. R., Phosiwa M. N., Al Busaidy R. M., Al Ismaaily S. I.: Lumpy skin disease of cattle: an emerging problem in the Sultanate of Oman. Trop. Anim. Health Pro. 2014, 46, 241-246.

18. Tasioudi K. E., Antoniou S. E., Iliadou P., Sachpatzidis A., Plevraki E., Agianniotaki E. I., Fouki C., Mangana-Vougiouka O., Chondrokouki E., Dile C.: Emergence of lumpy skin disease in Greece, 2015. Transbound. Emerg. Dis. 2016, 63, 260-265.

19. Tuppurainen E. S. M.: Lumpy Skin Disease, [in:] Vallat B., Caporale V. (eds): Manual of Diagnostic Tests and Vaccines for Terrestrial Animals. World Organization for Animal Health (OIE), Paris 2012, 762-774.

20. Tuppurainen E. S. M., Oura C. A. L.: Review: lumpy skin disease: An emerging threat to Europe, the Middle East and Asia. Transbound. Emerg. Dis. 2012, $59,40-48$.

21. Tuppurainen E. S. M., Stoltsz W. H., Troskie M., Wallace D. B., Oura C. A. L., Mellor P. S., Coetzer J. A. W., Venter E. H.: A potential role for ixodid (hard) tick vectors in the transmission of lumpy skin disease virus in cattle. Transbound. Emerg. Dis. 2011, 58, 93-104.

22. Tuppurainen E. S. M., Venter E. H., Coetzer J. A. W.: The detection of lumpy skin disease virus in samples of experimentally infected cattle using different diagnostic techniques. Onderstepoort J. Vet. 2005, 72, 153-164.

Corresponding author: Assoc. Prof. Dr. Harun Albayrak, Department of Virology, Faculty of Veterinary Medicine, Ondokuz Mayis University, 55200, Samsun, Turkey; e-mail: harunalbayrak55@msn.com; harun.albayrak (a)omu.edu.tr 